\title{
Seasonal variation of gravity waves in the Equatorial Middle Atmosphere: results from ISRO's Middle Atmospheric Dynamics (MIDAS) program
}

\author{
G. Ramkumar ${ }^{1}$, T. M. Antonita ${ }^{1}$, Y. Bhavani Kumar ${ }^{2}$, H. Venkata Kumar ${ }^{2}$, and D. Narayana Rao ${ }^{2}$ \\ ${ }^{1}$ Space Physics Laboratory, VSSC, Trivandrum, India \\ ${ }^{2}$ National Atmospheric Research Laboratory, Gadanki, India
}

Received: 6 March 2006 - Revised: 20 July 2006 - Accepted: 24 August 2006 - Published: 20 October 2006

\begin{abstract}
Altitude profiles of temperature in the stratospheric and mesopheric region from lidar observations at NARL, Gadanki, India, during December 2002-April 2005, as part of ISRO's Middle Atmospheric Dynamics - "MIDAS (2002-2005)" program are used to study the characteristics of gravity waves and their seasonal variation. Month-tomonth variation of the gravity wave activity observed during the period of December 2002-April 2005 show maximum wave activity, with primary peaks in May 2003, August 2004 and March 2005 and secondary peaks in February 2003 and November 2004. This month-to-month variation in gravity wave activity is linked to the variation in the strength of the sources, viz. convection and wind shear, down below at the tropospheric region, estimated from MST radar measurements at the same location. Horizontal wind shear is found to be mostly correlated with wave activity than convection, and sometimes both sources are found to contribute towards the wave activity.
\end{abstract}

Keywords. Meteorology and atmospheric dynamics (Climatology; Convective processes; Middle atmosphere dynamics)

\section{Introduction}

The equatorial middle atmosphere hosts a wide range of processes, which are dynamically coupled with lower and upper regions of the Earth's atmosphere. Many studies have suggested that the equatorial oscillations influence the global atmospheric circulation and structure in prominent ways. During the past two decades, five equatorial wave campaigns were conducted, involving several Indian stations, to study the characteristics of equatorial waves and gravity waves and also to estimate the momentum fluxes associated with

Correspondence to: G. Ramkumar

(geetha_ramkumar@vssc.gov.in) these waves (Sasi et al., 2005). The experience and expertise gained from these campaigns set the tone for another five-year long national program known as "ISRO's Middle Atmosphere Dynamics Program - MIDAS (2002-2005)", which has been proposed and executed by Space Physics Laboratory (SPL) of Vikram Sarabhai Space Centre (VSSC), Trivandrum. This program started on 21 November 2002, to commemorate the first rocket (Nicke-Apache) launch from the Thumba Equatorial Rocket Launching Station (TERLS) at VSSC. The MIDAS program mainly consists of three themes which address the following scientific objectives:

1. To obtain gravity wave climatology in the middle atmosphere over the low-latitude Indian region and to study the impact of gravity waves in the evolution of easterly and westerly phases of the stratopause and mesopause zonal wind Semi-Annual Oscillations (SAO). (ThemeI).

2. To study the phase difference between the high-latitude "stratospheric warming" and low-latitude "stratospheric cooling" and the evolution of the middle atmospheric circulation changes during stratwarm events. (ThemeII).

3. To study the mutual coupling between the middle atmospheric circulation changes and the "monsoon" phenomenon. (Theme-III).

Under Theme-I of this program, regular coordinated measurements of winds and temperatures are made fortnightly using in-situ measurements such as High Altitude Balloon (HAB) flights and Rohini Sounding Rocket-RH 200 flights, ground-based measurements using Partial Reflection Radar (PRR) and SKiYMET Meteor Wind radar from TERLS, Trivandrum $\left(8.5^{\circ} \mathrm{N}, 77^{\circ} \mathrm{E}\right)$, PRR measurements from Equatorial Geophysical Research Laboratory (EGRL), Tirunelveli $\left(8.7^{\circ} \mathrm{N}, 77.8^{\circ} \mathrm{E}\right)$ and MST radar and lidar measurements at

Published by Copernicus GmbH on behalf of the European Geosciences Union. 
Table 1. Experiments under MIDAS program.

\begin{tabular}{c|c|c|c|c|c|c}
\hline Instrument & $\begin{array}{c}\text { RH-200 } \\
\text { Rockets } \\
\text { (TERLS) }\end{array}$ & $\begin{array}{c}\text { High-altitude } \\
\text { Balloons } \\
\text { (TERLS) }\end{array}$ & $\begin{array}{c}\text { Lidar } \\
\text { (Gadanki) }\end{array}$ & $\begin{array}{c}\text { PR Radar } \\
\text { (TERLS } \\
\text { and } \\
\text { Tirunelveli) }\end{array}$ & $\begin{array}{c}\text { MST } \\
\text { Radar } \\
\text { (Gadanki) }\end{array}$ & $\begin{array}{c}\text { SKiYMET } \\
\text { Meteor Radar } \\
\text { (TERLS) }\end{array}$ \\
\hline $\begin{array}{c}\text { Measured } \\
\text { parameters }\end{array}$ & Wind & $\begin{array}{c}\text { Wind, } \\
\text { Temperature }\end{array}$ & Temperature & Wind & Wind & Wind \\
\hline $\begin{array}{c}\text { Height } \\
\text { region (km) }\end{array}$ & $20-65$ & $0-35$ & $30-70$ & $65-95$ & $\begin{array}{c}3--20 \\
70-90\end{array}$ & $80-110$ \\
\hline $\begin{array}{c}\text { Time (h) } \\
\text { Frequency of } \\
\text { measurement }\end{array}$ & Fortnightly & Fortnightly & Fortnightly & Fortnightly & Fortnightly & Daily \\
\hline
\end{tabular}

NARL, Gadanki $\left(13.5^{\circ} \mathrm{N}, 79.2^{\circ} \mathrm{E}\right)$. Table 1 shows the details of the experiments conducted regularly under this program.

Objectives under Theme (II) and (III) will be realized through a 15-day long campaign based observations, using all the above experiments shown in Table 1 , in addition to lidar observations from Mount Abu $\left(24.5^{\circ} \mathrm{N}, 72.7^{\circ} \mathrm{E}\right)$ and HAB flights from five additional MET stations over the Indian subcontinent. Two such campaigns were already conducted during July-August 2005 (monsoon campaign) and January-February 2006 (stratwarm campaign).

Using the data collected under three themes and also using the data collected from other co-located experiments in SPL, the following scientific issues will also be addressed: (a) characterising the variability of the lower stratospheric Quasi-Biennial Oscillation (QBO), stratopause and mesopause semiannual oscillations (SSAO, MSAO) and annual oscillations $(\mathrm{AO})$ in the tropical middle atmosphere and exploring a physical relationship between QBO, SAO characteristics and certain aspects of the Indian Monsoon, (b) the relationship between the stratospheric and mesospheric circulation features (mean wind, wave perturbations etc.) and Equatorial Electrojet (EEJ) and Counter Electrojet (CEJ) phenomena.

It is well known that the momentum and energy fluxes transported and deposited by gravity waves induce mean zonal and meridional circulation, and thus affect the temperature distribution and turbulent diffusion of heat and constituents in the stratosphere and mesosphere (Strobel et al., 1985; Palmer et al., 1986; Miyahara et al., 1986). Large temperature inversions observed in the mesosphere, which persist for several days, are found to be induced by gravity wave breaking (Hauchecorne et al., 1987; Hauchecorne and Maillard, 1990). Though the understanding of gravity waves in the middle atmosphere has improved a great deal during the last 3-4 decades, interest in this field continues to increase and the effects continue to become better and better understood. Recent ground-based and space-based observational studies and numerical and theoretical studies have contributed a great deal towards the source characteristics, spectra, fluxes, energy transfer, wave-mean flow interaction, wave-wave interaction and their implications for atmospheric dynamical structures, etc. (Wilson et al., 1991a, b; Beatty et al., 1992; Tsuda et al., 2000; Kawatani et al., 2004). Studies on gravity wave climatology in the middle atmosphere using Rayleigh lidar observations from two stations in South France $\left(44^{\circ} \mathrm{N}\right)$ during 1986 to 1989 by Wilson et al. (1991b) showed an annual variation with winter maximum and a semiannual variation with a secondary maximum in summer. Most of the studies on gravity wave activity are from mid latitudes and unfortunately there have been very few gravity wave studies conducted at the low-latitude middle atmosphere. Of course there are studies on gravity wave activity in the low-latitude tropospheric and lower stratospheric regions using radar observations (Dutta et al., 1999; Dhaka et al., 2001, 2002) and mesospheric temperature structure and inversion using lidar observations (Siva Kumar et al., 2001, 2003, 2004; Krishnaiah et al., 2004; Bhavani Kumar et al., 2000). Theoretical and observational studies using radiosonde and rocket flights also could provide information on the seasonal and latitudinal variations of gravity wave activity (Eckermann et al., 1995; Alexander and Vincent, 2000; Alexander et al., 2002). Fritts and Alexander (2003) have done a thorough review of the studies on gravity waves, their sources, characteristics, and influences on large-scale circulation and draw attention towards the areas in which further progress is required.

One of the main objectives of MIDAS is to study the climatology of gravity wave activity and this study from a lowlatitude station is crucial in understanding the dynamics of the equatorial middle atmosphere. But the present study is 
aimed at bringing out the seasonal variation of the gravity wave activity, using temperature data collected during 20022005 from the NARL Rayleigh lidar and linking this to the variation in the strength of the source in the lower atmosphere, viz. convection and wind shear observed from the co-located MST radar measurements. A study on the climatology of gravity waves will be made after the completion of the program.

\section{Data and method of analysis}

Under the MIDAS program, fortnightly observations (alternate Wednesdays) were conducted using lidar at NARL, in order to obtain temperature data in the middle atmosphere, in connection with the balloon, rocket flights and associated ground-based experiments. In addition to the $6-8 \mathrm{~h}$ of observations on alternate Wednesdays, more than $4 \mathrm{~h}$ of observations were also conducted for 2 or more days during that week and these form the basic data used for the present study. There was a gap in the lidar data during June 2003 to October 2003, due to maintenance of the lidar. Though data was available for November 2003-Febrauary 2004, it was not used in the present study due to large errors involved. Continuous data sets are available from March 2004 onwards and the MIDAS program is successfully going on. The present study makes use of 4-6h (20:00-01:00 LT) of temperature data on all available days of observation during December 2002 to April 2005. Figure 1 shows the histogram of the number of days of observation during each month covering the above period of more than 2 years. The total number of days of observation that are used for this present study amounts to around 100 out of the totally available 266 days.

The lidar at NARL makes use of the Nd-YAG laser with a 532-nm wavelength and the power of 0.4 joules/pulse. The temperature profiles along with the errors were estimated (Parameswaran et al., 2000) in the 27-70 km altitude region, with a temporal resolution of $250 \mathrm{~s}$ and a height resolution of $300 \mathrm{~m}$ from the photon counts detected by the lidar during the 4-6h of observations on each day. The profiles were further smoothed by averaging over three time bins and 3 range bins, in order to obtain temperature values at an interval of $12.5 \mathrm{~min}$, with a height resolution of $900 \mathrm{~m}$. Statistical error due to signal variance is $\sim 0.5-1 \mathrm{~K}$ in the $27-50 \mathrm{~km}$ and $\sim 2-$ $3.5 \mathrm{~K}$ at $65 \mathrm{~km}$. To minimize the uncertainty due to various errors, temperature data in the altitude region $27-60 \mathrm{~km}$ with a variation less than $10 \mathrm{~K}$ is used for the present study.

These time-height resolved temperature profiles are available for $4-6 \mathrm{~h}$ on each day of observation and are during the same time (20:00-01:00 LT). For studies of gravity wave characteristics, the time series of temperature fluctuations at the $12.5 \mathrm{~min}$ interval on each day, in the $27-60 \mathrm{~km}$ height region are derived by removing the mean temperature values for that day. This removes all the longer period oscillations and since the observation period remains the same through-

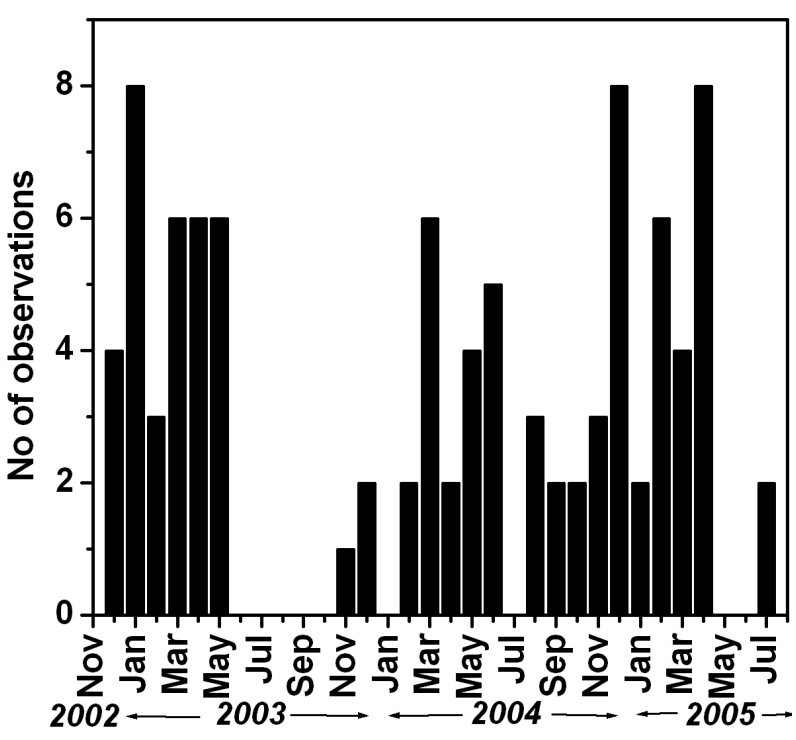

Fig. 1. Histogram showing the details of the observations for each month during 2002-2005.

out, the effect of the migrating tidal component also will be removed. The effect of diurnal, semidiurnal and terdiurnal non-migrating tidal components are negligible in the $4-6 \mathrm{~h}$ of observation.

To monitor the sources in the lower atmospheric region which give rise to the gravity waves, wind measurements in the 3-20 km height region, from MST radar observations on same day, are used. The MST radar operates at a frequency of $53 \mathrm{MHz}$ with a peak power of $2.5 \mathrm{MW}$, and a power aperture product of $3 \times 10^{10} \mathrm{Wm}^{-2}$ (Rao et al., 1995). The horizontal (zonal- $u$ and meridional- $v$ ) and vertical $(w)$ winds measured with an altitude resolution of $150 \mathrm{~m}$ and averaged over $3 \mathrm{~h}$ of observations are used for obtaining the strength of the wind shear and convective activity. The standard error in the measurement of $u, v, w$ in the $3-20 \mathrm{~km}$ height region are $0.2-$ $2.1 \mathrm{~m} / \mathrm{s}, 0.2-3 \mathrm{~m} / \mathrm{s}$ and $0.01-0.1 \mathrm{~m} / \mathrm{s}$, respectively.

\section{Results and discussions}

The height profiles of the time series of temperature fluctuations during 4-6h on each day of observation were used for identifying the prominent periodicities of gravity waves present and their propagation characteristics in the stratospheric and mesospheric regions. The spectral amplitudes, in turn, were used to derive the potential energy associated with each period, which is a measure of the strength of wave activity. Figures $2 \mathrm{a}, \mathrm{b}$ show the time variation of the temperature fluctuations for two sample days, viz. 19 December 2002 and 10 April 2004. The fluctuations in Fig. 2a clearly show the presence of periodicities mainly in the range of 3$4 \mathrm{~h}$, whereas Fig. $2 \mathrm{~b}$ shows the periodicities in the range of 

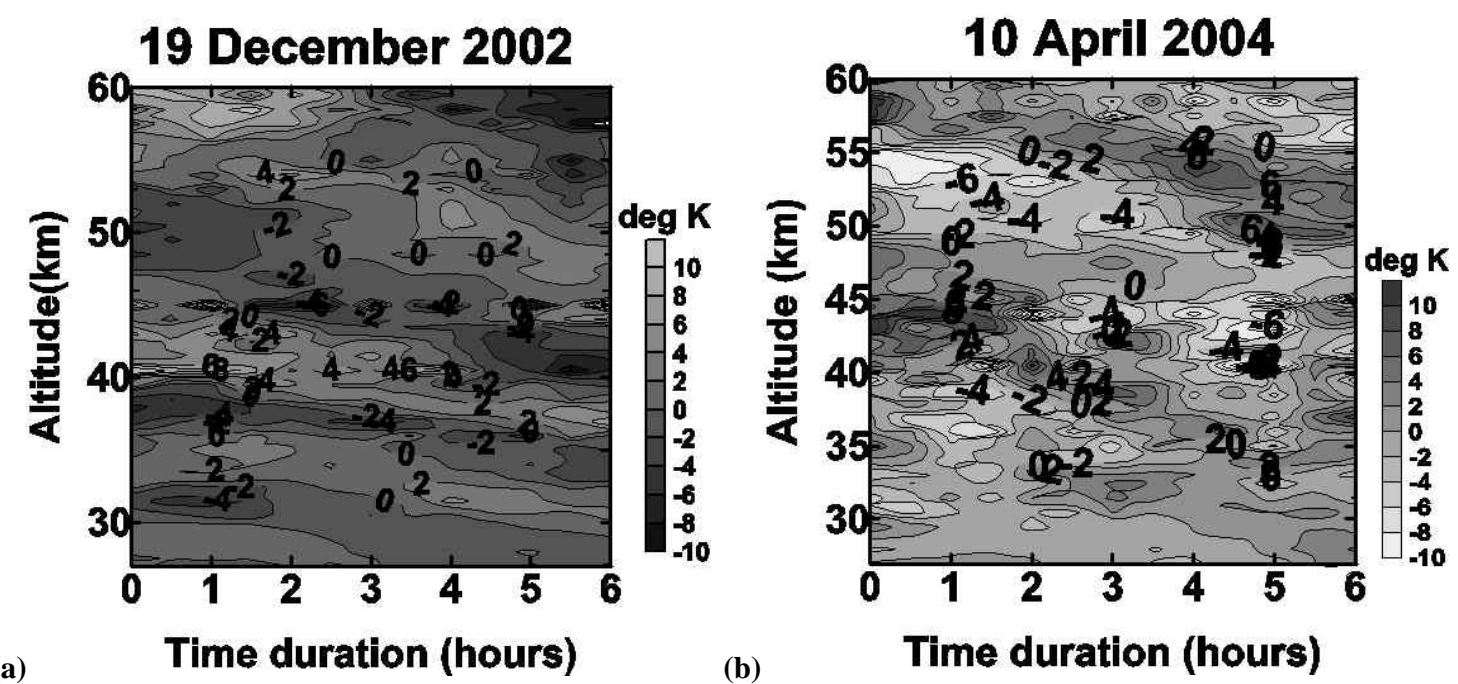

Fig. 2. Time-height section of the mean removed temperature fluctuations during $6 \mathrm{~h}$ of observation.

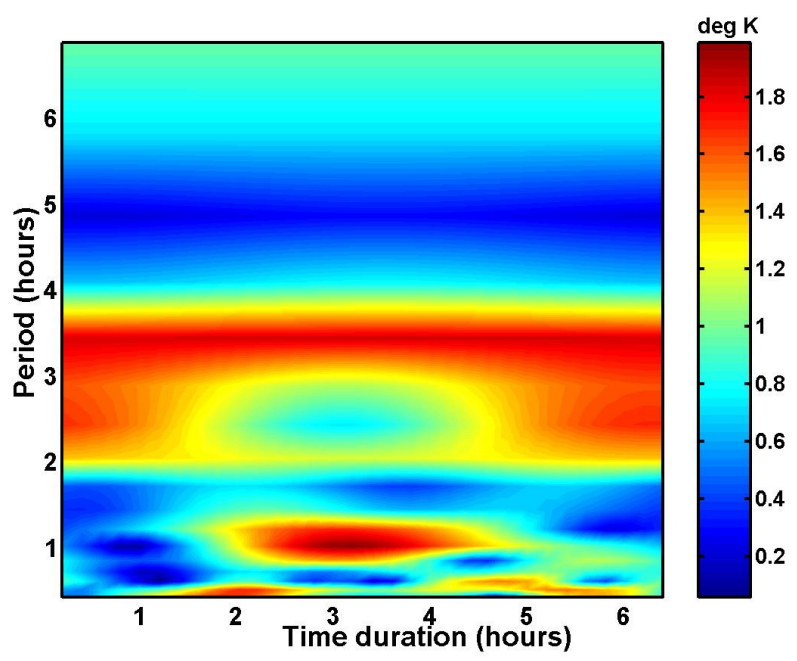

Fig. 3. Wavelet spectrum of gravity waves showing prominent periodicities.

$2-4 \mathrm{~h}$. Downward phase propagation with height is seen in both figures. The presence of longer periods like $6 \mathrm{~h}$ or more are also indicated.

The time series of temperature fluctuations were subjected to Maximum Entropy Method (MEM) spectral analysis and Morlet wavelet analysis, to look for the prominent periodicities present in the data. Both could indicate the presence of a $2-4 \mathrm{~h}$ period and a $30 \mathrm{~min}-1 \mathrm{~h}$ period. Figure 3 is a typical spectrum of the periodicities derived using wavelet analysis (Torrence and Compo, 1998) at a height of $45 \mathrm{~km}$ in which the $2-4 \mathrm{~h}$ period and $30 \mathrm{~min}-1 \mathrm{~h}$ period are found to be prominently present in the data. Since the prominent periods present are in these ranges $(2-4 \mathrm{~h}, 30 \mathrm{~min}-1 \mathrm{~h})$, we are fo- cussing the present study on these two bands of periodicities of gravity waves.

\subsection{Propagation characteristics}

In order to study the vertical propagation characteristics of gravity waves in these two bands of periodicities, spectral analysis was performed on the time series of temperature fluctuations in the $27-60 \mathrm{~km}$ height region, on each day of observation. In the $6 \mathrm{~h}$ and $4 \mathrm{~h}$ data length, there can be 3016 numbers of profiles at the $12.5 \mathrm{~min}$ interval. It may be noted that since 30-16 data points are included in the FFT analysis at each altitude, the standard error in the amplitude is reduced by $\sqrt{ } 30-\sqrt{ } 16$. Figures $4 a-e$ show the sample height profiles of the amplitudes and phases of $4 \mathrm{~h}, 3 \mathrm{~h}$, $2 \mathrm{~h}, 1 \mathrm{~h}$ and $30 \mathrm{~min}$ period gravity waves along with the errors in the estimated amplitudes and phases. These errors in amplitude and phase are estimated using the error propagation formula (Whittaker and Robinson, 1965). Generally, all the amplitude profiles show an exponential increase with height, and the phase structure shows a decreasing trend with height, especially in the $30-45 \mathrm{~km}$ and $50-60 \mathrm{~km}$ regions. In Fig. $4 \mathrm{a}$, the amplitude of the $4 \mathrm{~h}$ period reaches a maximum of $8 \mathrm{~K}$ at the $45 \mathrm{~km}$ altitude, and the phase shows a clear downward propagation in the $40-55 \mathrm{~km}$ height region with a vertical wavelength of $12 \mathrm{~km}$. For the $3 \mathrm{~h}$ period, the altitude structure of the amplitude and phase is shown in Fig. 4b. The maximum amplitude is $\sim 5 \mathrm{~K}$ and it shows a steady increase with height throughout the $30-60 \mathrm{~km}$ region. The phase structure shows a decreasing tendency in the $37-45$ and $50-60 \mathrm{~km}$ height regions, with a vertical wavelength of $8-12 \mathrm{~km}$. Figure $4 \mathrm{c}$ shows the height structure of the amplitude and phase of the $2 \mathrm{~h}$ period gravity wave. Similar to other periods, this also shows exponential growth in 
(a)

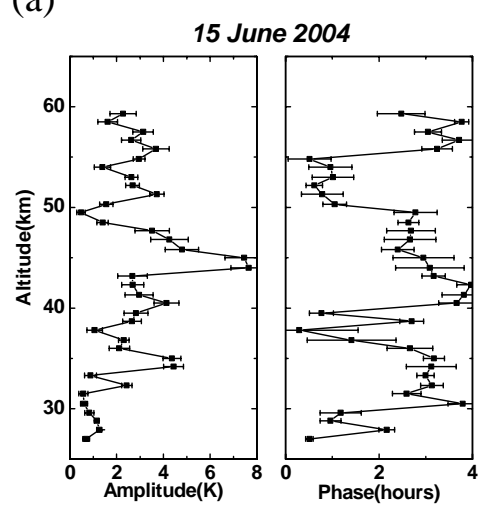

(b)

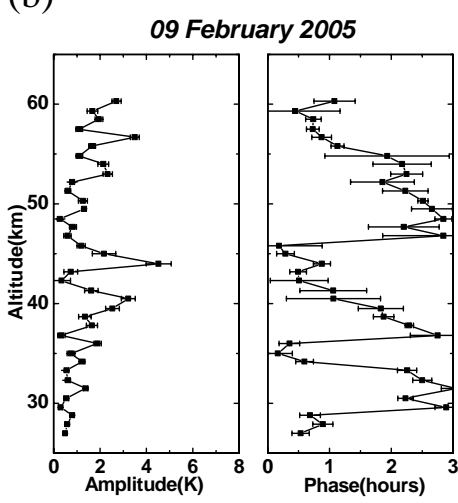

(c)

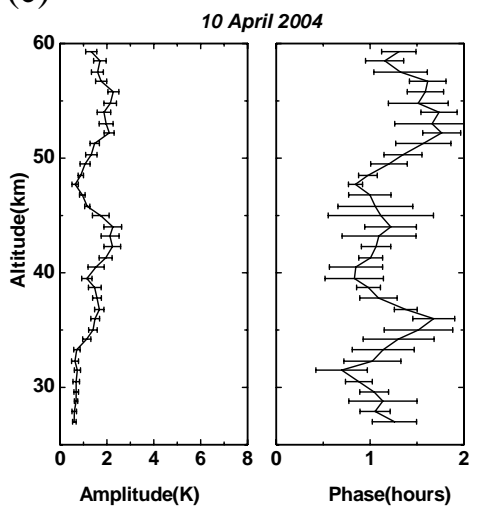

(d)

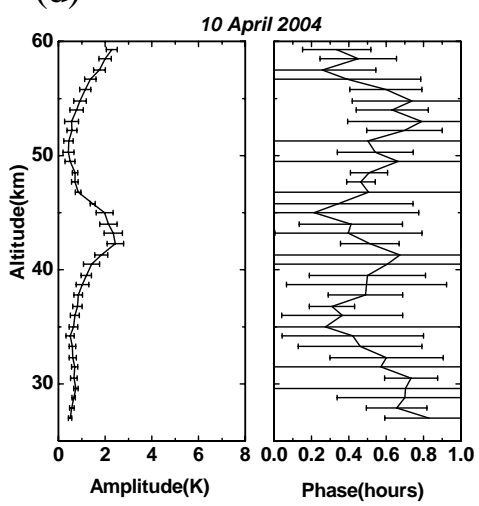

(e)

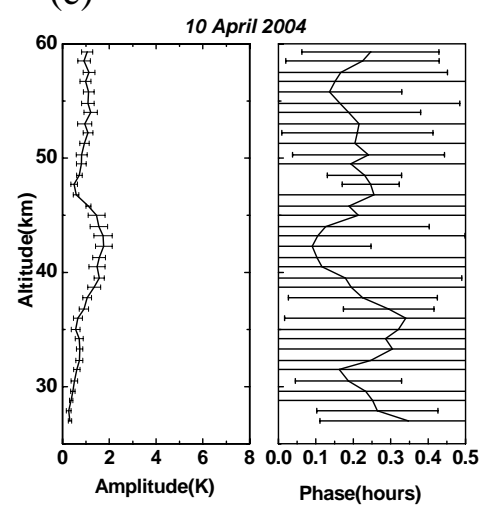

Fig. 4. Height profiles of amplitude and phase for $4 \mathrm{~h}(\mathbf{a}), 3 \mathrm{~h} \mathrm{(b)}, 2 \mathrm{~h} \mathrm{(c),} 1 \mathrm{~h}(\mathbf{d})$ and $30 \mathrm{~min}(\mathbf{e})$ period gravity waves.

amplitude with a maximum of $3 \mathrm{~K}$ around the $45 \mathrm{~km}$ height region. The phase structure shows a downward propagation in the 27-32, 35-40 and 50-58 km height regions, with a vertical wavelength of $\sim 5 \mathrm{~km}$. The error in phase estimation is slightly larger due to smaller amplitudes. Gravity waves in the $1 \mathrm{~h}$ and $30 \mathrm{~min}$ period (Figs. $4 \mathrm{~d}$, e) show a growth of amplitude in the $30-45 \mathrm{~km}$ altitude region, reaching a maximum amplitude of $2-3 \mathrm{~K}$ at $45 \mathrm{~km}$. The phase structure for the $1 \mathrm{~h}$ period shows a downward trend in the $30-35 \mathrm{~km}, 41-45 \mathrm{~km}$ and $53-59 \mathrm{~km}$ height regions with a vertical wavelength of $\sim 10 \mathrm{~km}$. In the case of the $30 \mathrm{~min}$ period, the phase structure shows a decreasing trend in the $27-32 \mathrm{~km}, 35-43 \mathrm{~km}$ and $48-58 \mathrm{~km}$ height regions, with a vertical wavelength of $12-15 \mathrm{~km}$. Errors in phase appear large, sometimes maximum of even $1 \mathrm{~h}$ and $30 \mathrm{~min}$ are seen when amplitudes are very small. The amplitude structure also shows same range of vertical wavelengths.

\subsection{Potential energy of gravity waves}

The potential energy (PE) of the gravity wave per unit mass at any altitude $\mathrm{Z},\left(\mathrm{E}_{P}(\mathrm{Z})\right)$ for a particular periodicity can be calculated using the equation (Wilson et al., 1991a).
$E_{p}(Z)=\frac{1}{2}\left(\frac{g(z)}{N(z)}\right)^{2}\left[\frac{T^{\prime}(z)}{T_{0}(z)}\right]^{2}$,

where $g(Z)$ is the acceleration due to gravity, $N(Z)$ is the Brunt-Väisälä frequency (calculated from mean temperature), $T /(Z)$ is the amplitude for a particular period, $T_{0}(Z)$ is the mean temperature.

During each observation day, for periods in the range of $30 \mathrm{~min}$ to $4 \mathrm{~h}$, the PE values were calculated in the $27-60 \mathrm{~km}$ height region. The PE values calculated for all days of observation during one month were averaged to obtain the monthly profile of gravity wave activity for the two bands ( $2-4 \mathrm{~h}$ and 30 min $-1 \mathrm{~h}$ ) of periods.

The altitude profiles of potential energy for the $2-4 \mathrm{~h}$ and $30 \mathrm{~min}$ to $1 \mathrm{~h}$ period gravity waves for the representative months (June 2004, September 2004, December 2004, and April 2005) in each season are shown in Fig. 5. The error bars are also presented along with the altitude variation of the PE values. Although the r.m.s. deviation of less than $10 \mathrm{~K}$ in temperature measurement in the region below $60 \mathrm{~km}$ will lead to an increased deviation in PE values $\left(T^{\prime} / T_{0}^{2}\right)$, the error in the PE values will be reduced while averaging for all 

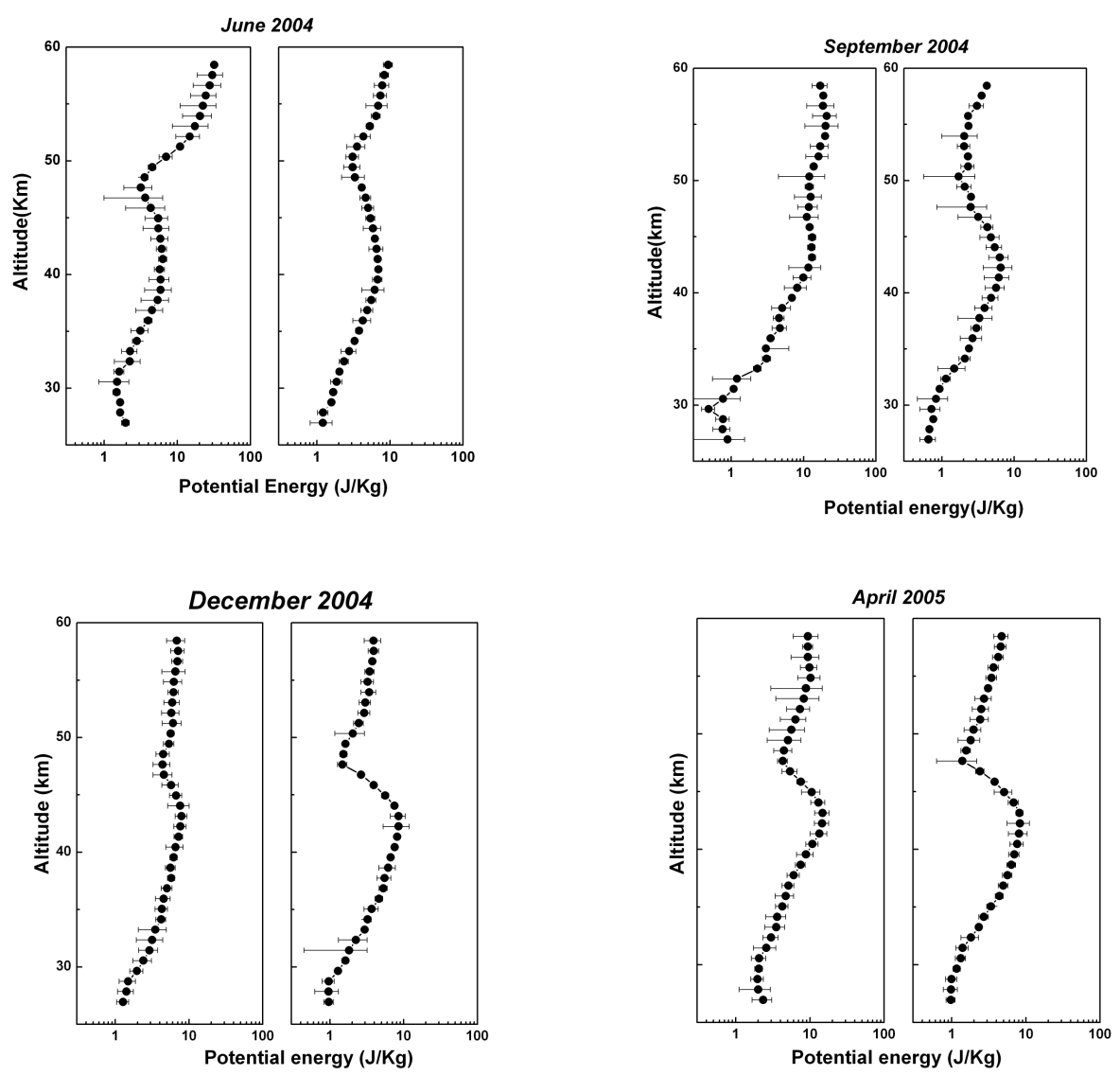

Fig. 5. Height profiles of potential energy of $2-4 \mathrm{~h}$ period (left panel) and $30 \mathrm{~min}-1 \mathrm{~h}$ period (right panel) gravity wave, for the representative month in each season.

the days of observations in a particular month. During the pre-monsoon (April-May) and monsoon (June-September) months due to cloudy sky conditions, a limited number of days of observations are available and hence the errors are found to be large (for example, June 2004 and April 2005). Again these errors in PE are smaller at altitudes below $50 \mathrm{~km}$ and they increase above that. Generally, the value of the observed PE increases with altitude in the stratosphere and mesosphere. The rate of growth is different in the different regions of atmosphere such as $30-35 \mathrm{~km}, 35-45 \mathrm{~km}$ and $45-$ $60 \mathrm{~km}$. In the mesospheric region, the observed variation is less than or equal to that in the stratospheric region for most of the months, indicating a dissipation of wave energy as it goes up. The growth and dissipation of the wave as it propagates up is influenced by the background wind condition that prevails. From the dissipation rate and divergence of momentum flux of these waves, it is possible to quantify the contribution of gravity waves towards the mean flow acceleration generating SAO, which form part of another paper. In the present study, we are focusing on the wave activity in two height regions, viz. 30-45 and 45-60 km regions and hence the PE values are averaged in these two specific height regions for further study of the seasonal variation.

\subsection{Seasonal variation of gravity wave activity}

The potential energy values averaged in each month were again smoothed by averaging the energy values in the height range $30-45 \mathrm{~km}$ and $45-60 \mathrm{~km}$, to look for the seasonal variation in the activity for two bands of periodicities. Figure $6 \mathrm{a}$ shows the month-to-month variation of gravity wave activity for 2-4h bands in all the available months of observations during December 2002-April 2005. The lower panel describes the PE values for the $2-4 \mathrm{~h}$ period waves averaged in the $30-45 \mathrm{~km}$ height region and the upper panel is for the averaged PE values in the $45-60 \mathrm{~km}$ region. From December 2002-May 2003 and March 2004-April 2005, we could obtain continuous temperature data (except July 2004). During August 2004 in the $45-60 \mathrm{~km}$ height range, the error is slightly larger compared to other months. The PE values generally vary between $8 \mathrm{~J} / \mathrm{Kg}$ to $20 \mathrm{~J} / \mathrm{Kg}$ in the $30-45 \mathrm{~km}$ region, except in May where the values go up to $30 \mathrm{~J} / \mathrm{kg}$ but with large errors. In the $45-60 \mathrm{~km}$ region, PE values vary from $8 \mathrm{~J} / \mathrm{kg}$ to $35 \mathrm{~J} / \mathrm{kg}$. Figure $6 \mathrm{~b}$ shows the month-tomonth variation of the gravity wave activity for the $30 \mathrm{~min}-$ $1 \mathrm{~h}$ band in all available months of observation during December 2002-April 2005. The PE values in the $45-60 \mathrm{~km}$ 


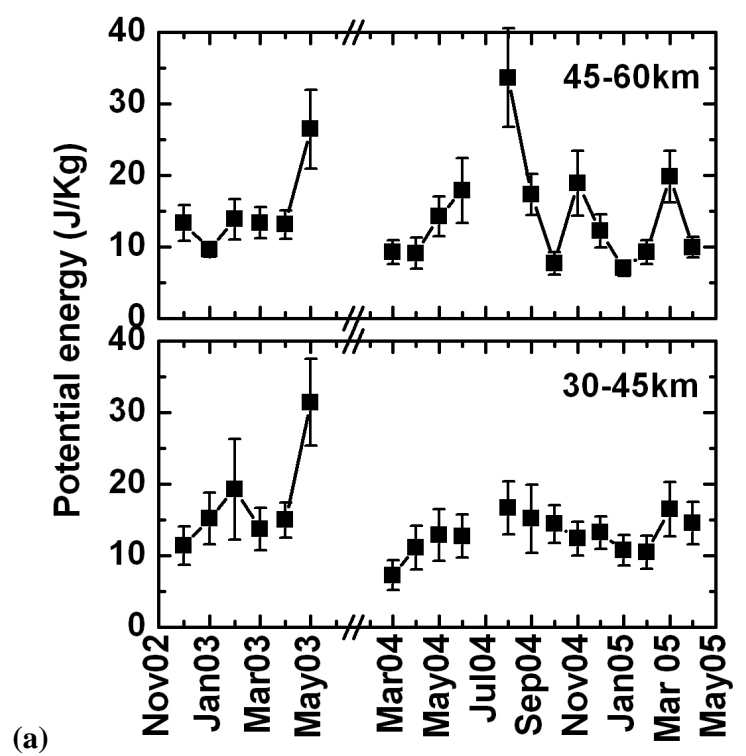

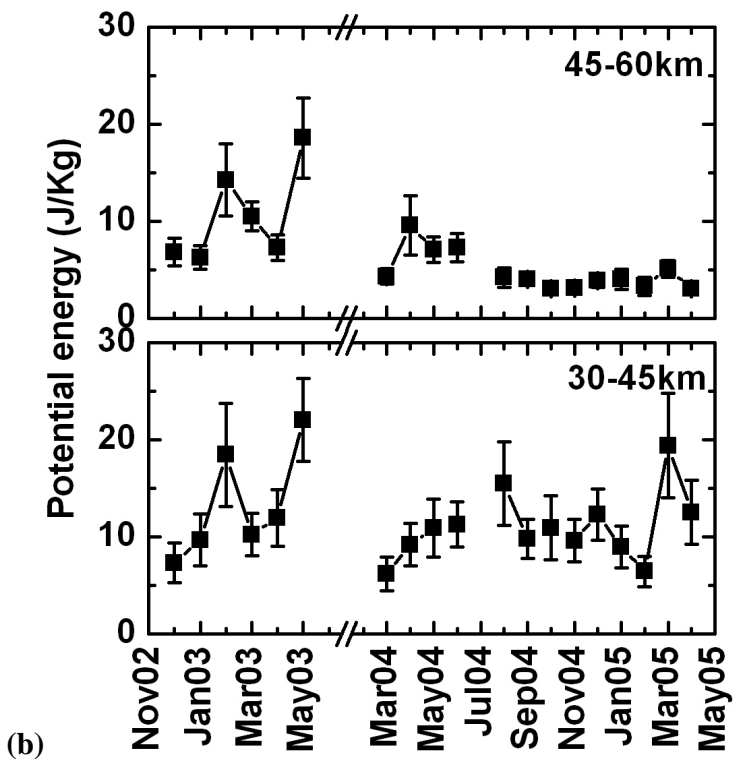

Fig. 6. The month-to-month variation of potential energy of gravity waves of the (a) $2-4 \mathrm{~h}$ period and (b) $30 \mathrm{~min}-1 \mathrm{~h}$ period during December 2002-April 2005. Lower panel corresponds to 30-45 km and upper panel corresponds to $45-60 \mathrm{~km}$.

region during August 2004-April 2005 are comparatively less. The PE values are found to vary from $5 \mathrm{~J} / \mathrm{kg}$ to a maximum of $20 \mathrm{~J} / \mathrm{kg}$. The variation in the wave activity is almost similar to that in the $2-4 \mathrm{~h}$ band, both in the $30-45 \mathrm{~km}$ and $45-60 \mathrm{~km}$ regions.

Generally, a semiannual variation is seen in the gravity wave activity over the whole period of observation and it becomes clearer during 2004-2005. A major peak in wave activity is seen in May 2003 and August 2004 (even after taking into account the large error in the estimated PE) and a secondary peak is seen in March 2005 in the case of the 2-4 h gravity waves. The enhancement of wave activity in November 2004 could be associated with a strong convective event during that time. In the case of the $30 \mathrm{~min}-1 \mathrm{~h}$ period gravity waves, peaks are seen in February 2003, May 2003, August 2004 and March 2005. Generally the wave activity is found to be minimum in the winter months (December and January) for both bands of periodicities.

With the available data during 2002-2005, it can be seen that the year-to-year variation in wave activity is not very pronounced, but a slight increase is seen during 2003 and 2005 compared to 2004 (for example, March). During the summer and winter monsoon months, obtaining clear sky conditions and better data from this location is very difficult. Still from the temperature data collected during the 4$8 \mathrm{~h}$ of observations and on all available days of observations in each month, better data was selected and was utilized for the present study.

\subsection{Variation of gravity wave activity and source strength}

The major sources of gravity waves include topography, convection and wind shear. In addition to this, other sources, such as unbalanced flows in the vicinity of the jet streams, frontal systems and wave-wave interaction also generate these gravity waves. Although it has been known for decades that convection can excite gravity waves, there is still controversy and ongoing research aimed at understanding this generation mechanism. It is seen that waves generated by topography and convection are characterized by a wide range of frequencies, vertical and horizontal scales and phase speeds.

Along with lidar observation, under the MIDAS program, the horizontal and vertical wind measurements in the lower and upper atmospheric region were also made for $2 \mathrm{~h}$ using the MST radar at the same location. In an attempt to link the variation in the gravity wave activity in the middle atmospheric region with the variation in source strength, viz. convection (updraft in vertical winds) and wind shear in the horizontal winds in the lower atmospheric region, the horizontal and vertical winds estimated from MST radar are averaged in the $4-10 \mathrm{~km}, 10-15 \mathrm{~km}$ and $15-20 \mathrm{~km}$ height region for each month. The large, positive vertical wind values indicating an updraft are a measure of convective activity and the horizontal wind shear can be calculated as $\sqrt{(d u / d z)^{2}+(d v / d z)^{2}}$. The month-to-month variation in potential energy of the $2-4 \mathrm{~h}$ gravity waves averaged over the 45-60 km height region for the period December 2002 to April 2005 was compared with the month-to-month variation in the horizontal wind shear (lower panel in Fig. 7a) and in the vertical winds (upper panel in Fig. 7a) averaged 

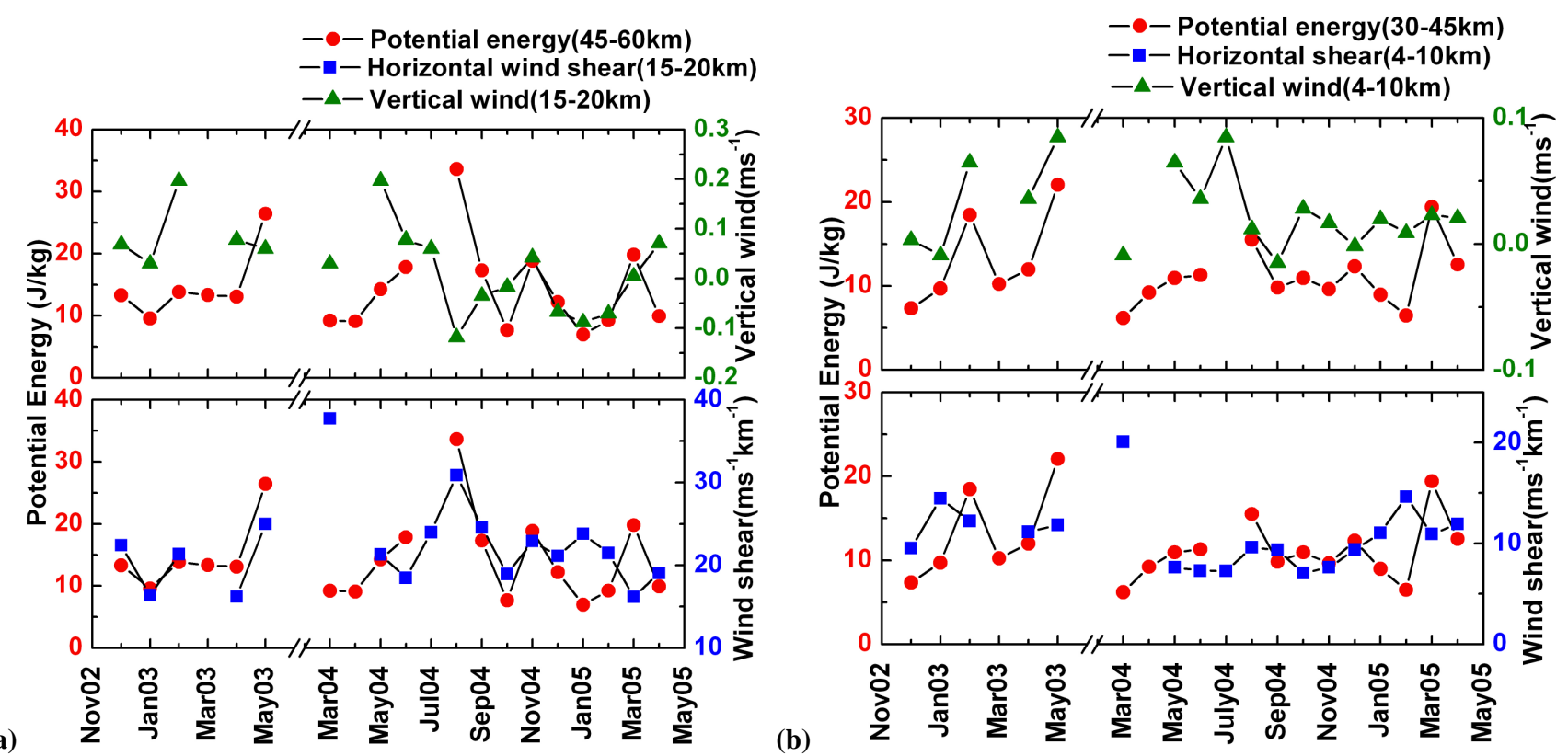

Fig. 7. Seasonal variation of potential energy (circle) correlated with strength of sources viz. horizontal wind shear (square) in the lower panel and vertical wind (triangle) in the upper panel for (a) 2-4 h period and (b) $30 \mathrm{~min}-1 \mathrm{~h}$ period.

over the height region of $15-20 \mathrm{~km}$. It is seen that the $2-$ $4 \mathrm{~h}$ period wave activity is well correlated with convection during December 2002-February 2003 and November 2004March 2005, whereas during December 2002-May 2003 and August-December 2004 it is more correlated with horizontal wind shear. During some months (December 2002-February 2003, and November-December 2004), the wave activity is well correlated with both sources. The correlation between the strength of the wave activity and the horizontal wind shear for the $2-4 \mathrm{~h}$ gravity wave during December 2002-May 2003 and August-December 2004 is found to be 0.98. Similarly a high correlation ( 0.98$)$ is seen between the strength of the $2-4 \mathrm{~h}$ gravity wave activity and the vertical winds during December 2002-February 2003 and November 2004-March 2005.

The month-to-month variation in PE of the 30 min- $1 \mathrm{~h}$ period gravity waves averaged over the $30-45 \mathrm{~km}$ height region for the period December 2002 to April 2005 was compared with the month-to-month variation in horizontal wind shear (lower panel in Fig. 7b) and in the vertical winds (upper panel in Fig. 7b) averaged over the height region of 4-10 km. From January-May 2003 (except March) and August- November 2004, the vertical wind (convection) contribution towards the wave activity seems to be greater. During December 2002January 2003 and November-December 2004, the horizontal wind shear is found to be contributing towards the wave activity. These features are indicative of the coupling process between the stratospheric and tropospheric regions of the atmosphere.

\section{Summary and concluding remarks}

The present study on gravity wave activity using temperature data in the middle atmospheric region for more than 2 years covering various seasons brings out the characteristic features of the prominent periodicities of gravity waves. Generally, it is seen that gravity waves of periods in the range 2-4 $\mathrm{h}$ and $30 \mathrm{~min}$ to $1 \mathrm{~h}$ show different propagation characteristics in the stratospheric and mesospheric regions. The vertical wavelength of the $2-4 \mathrm{~h}$ periodicities is found to be in the range of $5-12 \mathrm{~km}$ and that of $30 \mathrm{~min}-1 \mathrm{~h}$ is in the range of 10-15 km. From one year (March 2004-April 2005) of continuous observations, it is seen that a semiannual variation exists in the gravity wave activity with an enhancement in the wave activity in the August and March months. The daily wind and temperature fluctuations in the height range 20-65 km derived from meteorological rocket observations at many stations from $77^{\circ} \mathrm{N}$ to $8^{\circ} \mathrm{S}$ for several years (Hirota, 1984), could give gravity waves with characteristic vertical scales of $\sim 10 \mathrm{~km}$ and the gravity wave activity showed an annual cycle with the wintertime maximum at higher latitudes while it showed a semiannual cycle in the lower latitudes with the maxima around the equinoxes. It is also found from the same study that the temporal variability of the gravity waves is very large.

The variation in wave activity during December 2002April 2005 is compared with the variation in the strength of sources (viz. convection and wind shear) that excite these gravity waves of periods in the range of $30 \mathrm{~min}-1 \mathrm{~h}$ and $2-$ $4 \mathrm{~h}$. In the case of shorter period gravity waves, the strength 
of the wave activity is more correlated with vertical winds in the lower tropospheric region, which is a measure of the strength of convection. For gravity waves with medium frequencies, wave activity is found to be more correlated with horizontal wind shear in the upper tropospheric/lower stratospheric region. The mismatch in the correlation between the wave activity and source strength could be due to contribution from sources away from this location.

The background zonal winds at this low-latitude location vary with periods like semiannual, annual and quasi-biennial, and these are known to be capable of causing variations in the observable properties of the waves, even if the sources for the waves are constant in time. Thus, the variations observed in the wave activity could be caused by the wind shear in the stratosphere and the ability of the waves to propagate vertically without severe dissipation.

Studies by Preusse and Ern (2005) on gravity waves using CLAES temperature data on board UARS, and CRISTA horizontal wavelength analysis by Ern et al. (2004) showed that in the tropics, gravity wave activity at $25 \mathrm{~km}$ is dominated by long horizontal but moderate vertical wavelength waves and are subjected to strong dissipation. They also reported that at the $45 \mathrm{~km}$ altitude, waves with shorter horizontal wavelengths propagate almost vertically.

The Microwave Limb Sounder (MLS) instrument on board UARS provided stratospheric gravity wave data from 1991 to 1997 (Wu and Waters, 1997; Jiang et al., 2003, 2004, 2005) which could bring out multi-year climatologies and interannual variability and trends. The advanced microwave sounding unit (AMSU) (Wu, 2004) and the atmospheric infrared sounder (AIRS) on board the Aqua Satellite, launched in 2002, the second generation MLS instrument on board Aura launched in 2004, as well as the Global Position System (GPS) receivers carried by a number of current flying, low-Earth orbiters (LEOS) (Tsuda et al., 2000), etc., provide vast amounts of data with very high resolution. These experiments provide opportunities for gravity wave studies and observation-model comparisons that can resolve issues in the current understanding on stratospheric and mesospheric processes. Vincent and Alexander (2000) have studied the seasonal variation of gravity waves in the tropical lower stratosphere. Thus, most of these studies cover the $10-40 \mathrm{~km}$ altitude region of tropical latitudes and information from lowlatitude middle atmospheric region is very rare.

Although the global measurements of gravity waves at a range of stratospheric and mesospheric altitudes from high resolution satellite instruments are required for understanding the three-dimensional picture, such as intensity, seasonal and geographical variations of tropospheric sources of these waves, the clear picture of seasonal variation of wave activity and the corresponding sources that excite these waves, pertaining to our specific location, are not available from these studies. This could be achieved only by means of regular observations using ground-based vertical profiling instruments like lidar and radar. A scientific program like MIDAS (2002-
2005) is the most suitable one for such studies and it is the first of its kind to make use of long-term regular observations from NARL at Gadanki.

Acknowledgements. The authors express their sincere gratitude towards M. N. Sasi, M. Satya Narayana of Space Physics Laboratory and K. S. Appu, Retd. Manager, METF, Vikram Sarabhai Space Centre, ISRO, who are the other proposers of the MIDAS program. The authors duly acknowledge the support provided by the colleagues at NARL, especially V. K. Anandan and T. K. Ramkumar for conducting the Lidar and Radar experiments regularly for the program. The authors are thankful to Director, SPL and Chairman, ISRO for providing all the support required for smooth running of the program. We are also thankful to S. Jayakumar, and P. R. Suseela for the administrative support provided in the coordination of the MIDAS program. T. M. Antonita wish to thank ISRO for research fellowship.

Topical Editor U.-P. Hoppe thanks two referees for their help in evaluating this paper.

\section{References}

Alexander, M. J. and Vincent, R. A.: Gravity waves in the tropical lower stratosphere: A model study of seasonal and interannual variability, J. Geophys. Res., 105, 17 983-17 994, 2000.

Alexander, M. J., Tsuda, T., and Vincent, R. A.: Latitudinal variations observed in gravity waves with short vertical wavelengths, J. Atmos. Sci., 59, 1394-1404, 2002.

Beatty, T. J., Hostetler, C. A., and Gardner, C. S.: Lidar observations of gravity waves and their spectra near the mesopause and stratopause at Arecibo, J. Atmos. Sci., 49, 477-496, 1992

Bhavani Kumar, Y., Sivakumar, V., Rao, P. B., Krishnaiah, M., Mizutani, K., Aoki, T., Yasui, M., and Itabe, T.: Middle atmospheric temperature measurements, using ground based instrument at a low latitude, Indian J. Radio Space Phys., 29, 249-257, 2000.

Dhaka, S. K., Devarajan, P. K., Shibagaki, Y., Choudhary, R. K., and Fukao, S.: Indian MST Radar observations of gravity wave activities associated with tropical convection, J. Atmos. SolarTerr. Phys., 63, 1631-1642, 2001.

Dhaka, S. K., Choudhary, R. K., Malik, S., Shibagaki, Y., Yamanaka, M. D., and Fukao, S.: Observable signatures of a convectively generated wave field over the tropics using Indian MST radar at Gadanki $\left(13.48^{\circ} \mathrm{N}, 79.18^{\circ} \mathrm{E}\right)$, Geophys. Res. Lett., 29 (18), 1872, doi:10.129/2002GL014745, 2002.

Dutta, G., Bapiraju, B., Balasubramanyam, P., and Aleem Basha, H.: VHF Radar observations of gravity waves at a low latitude, Ann. Geophys., 17, 1012-1019, 1999,

http://www.ann-geophys.net/17/1012/1999/.

Eckermann, S., Hirota, I., and Hocking, W.: Gravity wave and equatorial wave morphology of the stratosphere derived from long-term rocket soundings, Q. J. R. Meteorol. Soc., 121, 149186(38), 1995.

Ern, M., Preusse, P., Alexander, M. J., and Warner, C. D.: Absolute values of gravity wave momentum flux derived from satellite data. J. Geophys. Res., 109, D20103, doi:10.1029/2004JD004752, 2004. 
Fritts, D. C. and Alexander, M. J.: Gravity wave dynamics and effects in the middle atmosphere, Rev. Geophys., 41(1), 1003, doi:10.1029/2001RG000106, 2003.

Hauchecorne, A., Chanin, M. C., and Wilson, R.: Mesospheric temperature inversion and gravity wave breaking, Geophys. Res. Lett., 14, 933-936, 1987.

Hauchecorne, A. and Maillard, A.: A 2D dynamical model of mesospheric temperature inversion in winter, Geophys. Res. Lett., 17, 2197-2200, 1990.

Hirota, I.: Climatology of gravity waves in the middle atmosphere, J. Atmos. Solar-Terr. Phys., 46, 767-773, 1984.

Jiang, J. H., Wu, D. L., Eckermann, S. D., and Ma, J.: Mountain waves in the middle atmosphere: Microwave Limb Sounder observations and analyses, Adv. Space Res., 32, 801-806, 2003.

Jiang, J. H., Wang, B., Goya, K., Hocke, K., Eckermann, S. D., Ma, J., Wu, D. L., and Reed, W. G.: Geographical distribution and interseasonal variability of tropical deep convection UARS MLS observations and analyses, J. Geophys. Res., 109(03), D03111, doi:10.1029/2003JD003756, 2004.

Jiang, J. H., Eckermann, S. D., Wu, D. L., Hocke, K., Wang, B., Ma, J., and Zhang, Y.: Seasonal variation of gravity wave sources from satellite observation, Adv. Space Res., 35, 19251932, 2005.

Kawatani, Y., Takahashi, M., and Tokioka, T.: Gravity waves around the subtropical jet of the southern winter in an atmospheric general circulation model, Geophys. Res. Lett., 31, L22109, doi:10.1029/2004GL020794, 2004.

Krishnaiah, M., Jaya Prakash Raju, U., Bhavani Kumar, Y., Raghunath, K., Siva Kumar V., Rao, P. B., Krishna Murthy, B. V., Sasi, M. N., Parameswaran, K., Krishna Murthy, K., and Nair, P. R.: Lidar observations of middle atmosphere temperature variability over low latitude, Indian J. Radio Space Phys., 33, 50-57, 2004.

Miyahara, S., Hayashi, I. Y., and Mahlman, J. D.: Interactions between gravity waves and the planetary scale flow simulated by the GFDL "SKYHI" general circulation model, J. Atmos. Sci., 43, 1844-1861, 1986.

Palmer, T. N., Shutts, G. J., and Swinback, R.: An elevation of a systematic westerly bias in general circulation and numerical weather prediction through an orographic gravity wave drag parameterization, Q. J. R. Meteorol. Soc., 12, 1001-1040, 1986.

Parameswaran, K., Sasi, M. N., Ramkumar, G., Nair, P. R., Deepa, V., Krishna Murthy, B. V., Prabhakaran Nayar, S. R., Revathy, K., Mrudula, G., Satheesan, K., Bhavanikumar, Y., Sivakumar, V., Raghunath, K., Rajendraprasad, T., and Krishnaiah, M.: Altitude Profiles of Temperature from 4 to $80 \mathrm{~km}$ over the tropics from MST Radar and Lidar, J. Atmos. Solar Terr. Phys., 62, 13271337, 2000.

Preusse, P. and Ern, M.: Indication of convectively generated gravity waves observed by CLAES, Adv. Space Res., 35, 1987-1991, 2005.
Rao, P. B., Jain, A. R., Kishore, P., Balamuralidhar, P., Damle, S. H., and Viswanathan, G.: Indian MST radar 1. System description and sample vector wind measurements in ST mode, Radio Sci., 30(4), 1125-1138, 1995.

Sasi, M. N., Ramkumar, G., and Krishna Murthy, B. V.: Studies on Equatorial waves over Indian zone - A Review, Current Science, 89, 475-487, 2005.

Siva Kumar, V., Bhavanikumar, Y., Raghunath, K., Rao, P. B., Krishnaiah, M., Mizutani, K, Aoki, T., Yasui, M., and Itabe, T.: Lidar measurements of mesospheric temperature inversion at a low latitude, Ann. Geophys., 19, 1039-1044, 2001, http://www.ann-geophys.net/19/1039/2001/.

Siva Kumar, V., Rao, P. B., and Krishnaiah, M.: Lidar measurements of stratosphere-mesosphere thermal structure at a low latitude Comparison with satellite data and models, J. Geophys. Res., 108(D11), 4342, doi:10.1029/2002JD003029, 2003.

Siva Kumar, V., Morel, B., Bencherif, H., Baray, J. L., Baldy, S., Hauchecorne, A., and Rao, P. B.: Rayleigh lidar observations of a warm stratopause over a tropical station, Gadanki $\left(13.5^{\circ} \mathrm{N}\right.$; 79.2 ${ }^{\circ}$ E), Atmos. Chem. Phys., 4, 1989-1996, 2004, http://www.atmos-chem-phys.net/4/1989/2004/.

Strobel, D. F., Aprizese, J. P., and Schoberl, M. R.: Energy balance constraints on gravity wave induced eddy diffusion in the mesosphere and lower thermosphere, J. Geophys. Res., 90, $13067-$ $13072,1985$.

Torrence, C. and Compo, G. P.: A Practical Guide to Wavelet Analysis, Bull. Amer. Meteor. Soc., 79, 61-78, 1998.

Tsuda, T., Nishida, M., Rocken, C., and Ware, R. H.: A global morphology of gravity wave activity in the stratosphere revealed by the GPS occultation data (GPS/MET), J. Geophys. Res., 105, 7257-7273, 2000.

Vincent, R. A. and Alexander, M. J.: Gravity waves in the tropical lower stratosphere: An observational study of seasonal and interannual variability. J. Geophys. Res., 105, 17 971-17 982, 2000.

Whittaker, E. and Robinson, G.: The calculus of observations, Blackie Acad. And Prof., New York, 1965.

Wilson, R., Chanin, M. L., and Hauchecorne, A.: Gravity waves in the middle atmosphere observed by Rayleigh lidar 1. Case studies, J. Geophys. Res., 96, 5169-5183, 1991a.

Wilson, R., Chanin, M. L., and Hauchecorne, A.: Gravity waves in the middle atmosphere observed by Rayleigh lidar 2. Climatology, J. Geophys. Res., 96, 5153-5165, 1991b.

Wu, D. L. and Waters, J. W.: Observations of gravity waves with the UARS Microwave Limb Sounder, Gravity wave Processes, NATOASI Series 1: Global Environment Change, 50, 103-120, 1997.

Wu, D. L.: Meso scale gravity wave variances from AMSU-A Radiances, Geophys. Res. Lett., 31, L12114, doi:10.1029/2004GL019562, 2004. 